\title{
UV and dietary predictors of serum 25-hydroxyvitamin D concentrations among young shift-working nurses and implications for bone density and skin cancer
}

\author{
Sarah C Wallingford ${ }^{1,2}+$, , Glenville Jones ${ }^{3}$, Lindsay C Kobayashi ${ }^{1,2,}+$, \\ Anne Grundy, ${ }^{1,}+$, Qun Miao ${ }^{1,2}$, Joan Tranmer ${ }^{1,4}$ and Kristan J Aronson 1,2,* \\ 'Department of Community Health and Epidemiology, Cancer Research Institute, Queen's University, Kingston, \\ ON K7L 3N6, Canada: 'Division of Cancer Care and Epidemiology, Queen's Cancer Research Institute, \\ Queen's University, Kingston, Ontario, Canada: ${ }^{3}$ Department of Biomedical and Molecular Sciences, Queen's \\ University, Kingston, Ontario, Canada: ${ }^{4}$ School of Nursing, Queen's University, Kingston, Ontario, Canada
}

Submitted 13 February 2013: Final revision received 3 May 2013: Accepted 20 May 2013: First published online 9 July 2013

\begin{abstract}
Objective: In 2011, the US Institute of Medicine updated the definition of vitamin $\mathrm{D}$ inadequacy to serum 25-hydroxyvitamin $\mathrm{D}(25(\mathrm{OH}) \mathrm{D})$ concentration of $30-<50 \mathrm{nmol} / 1$ and of deficiency to serum $25(\mathrm{OH}) \mathrm{D}<30 \mathrm{nmol} / \mathrm{l}$. We describe the prevalence of these conditions according to these definitions, seasonal variation in $25(\mathrm{OH}) \mathrm{D}$ and predictors of serum $25(\mathrm{OH}) \mathrm{D}$ concentrations among working, white women.

Design: Participants recorded lifestyle factors and dietary intake and provided fasting blood samples for measurement of serum 25(OH)D in both summer and winter. Predictors of serum $25(\mathrm{OH}) \mathrm{D}$ variation were analysed using linear regression and generalized linear mixed models.

Setting: Kingston General Hospital in Kingston, Ontario, Canada, from April 2008 to July 2009.

Subjects: Female premenopausal nurses ( $n$ 83) working full-time rotating shifts. Results: Deficient or inadequate vitamin D status was observed in $9 \%$ of participants following summer/autumn and in 13\% following winter/spring. Predictors of serum $25(\mathrm{OH}) \mathrm{D}$ concentration were vitamin $\mathrm{D}$ supplement use, tanning bed use and season. Tanning bed use increased serum 25(OH)D by $23 \cdot 24 \mathrm{nmol} / 1$ (95\% CI $8 \cdot 78$, 37.69 nmol/ $1, P=0 \cdot 002$ ) on average.

Conclusions: According to the 2011 Institute of Medicine bone health guidelines, over $10 \%$ of nurses had deficient or inadequate vitamin D status following winter. Higher serum concentrations were associated with use of tanning beds and vitamin D supplements. As health promotion campaigns and legal restrictions are successful in reducing tanning bed use among women, our data suggest that increased prevalence of vitamin D inadequacy and deficiency may be a consequence, and that low vitamin D status will need to be countered with supplementation.
\end{abstract}

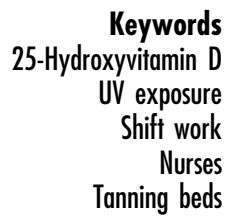

Vitamin D (or 25-hydroxyvitamin D, 25(OH)D) is a fat-soluble prohormone obtained primarily through solar UVB radiation exposure ${ }^{(1)}$. A well-documented lag time of 6-8 weeks exists between solar UVB exposure (or lack thereof) and resulting serum $25(\mathrm{OH}) \mathrm{D}$ concentrations ${ }^{(2)}$. Season and latitude are two main environmental determinants of $25(\mathrm{OH}) \mathrm{D}$ status, and from October to March at locations above $40^{\circ} \mathrm{N}$, solar UVB exposure is insufficient to permit cutaneous vitamin D synthesis due to the large solar radiation angle ${ }^{(3)}$. The term 'vitamin $\mathrm{D}$ winter' has been coined to describe this period of time ${ }^{(4)}$.

$\dagger$ Both affiliations are former affiliations of the author.
Increasing age, BMI and skin pigmentation are inversely related to serum $25(\mathrm{OH}) \mathrm{D}$ concentration ${ }^{(5,6)}$. Cloud coverage, air pollution, clothing coverage and sunscreen use decrease cutaneous vitamin D synthesis, as they interfere with skin UVB absorption ${ }^{(3-5)}$. Conversely, UVB radiation from sunny vacations and tanning bed use has been linked to increased $25(\mathrm{OH}) \mathrm{D}$ concentrations ${ }^{(7,8)}$. Natural and fortified foods and supplements are other sources of vitamin $\mathrm{D}^{(1,7)}$. Acute vitamin $\mathrm{D}$ toxicity can occur if serum concentration approaches or exceeds $375 \mathrm{nmol} / \mathrm{l}^{(9)}$, although some experts will cite $250 \mathrm{nmol} / \mathrm{l}$. Toxicity from dietary consumption is highly unlikely in the general population ${ }^{(10)}$. 
The US Institute of Medicine (IOM) has recently updated the definition of vitamin D deficiency (risk for rickets and osteomalacia) as serum 25(OH)D concentration $<30 \mathrm{nmol} / 1(12 \mathrm{ng} / \mathrm{ml})$ and the definition of inadequate vitamin $\mathrm{D}$ for bone health (risk of osteoporosis) as 30 to $<50 \mathrm{nmol} / 1(12 \text { to }<20 \mathrm{ng} / \mathrm{ml})^{(10)}$. Serum $25(\mathrm{OH}) \mathrm{D}$ concentrations below $50 \mathrm{nmol} / 1$ have been associated with a $30-50 \%$ increase in incidence and mortality of colon, prostate and breast cancers ${ }^{(11)}$, and concentrations above $100 \mathrm{nmol} / 1$ have been associated with a $62 \%$ decrease in risk of multiple sclerosis ${ }^{(12)}$. Solar UV exposure in early life has been associated with a $44 \%$ reduction in breast cancer risk in a prospective cohort of Swedish women $^{(13)}$ and with a $29 \%$ risk reduction in a case-control study of Canadian women ${ }^{(14)}$. However, the IOM review found that current evidence was insufficient to conclude a causal role for vitamin $\mathrm{D}$ in non-bone-related health conditions ${ }^{(10)}$.

Epidemiological studies of vitamin D status in relation to disease risk have traditionally employed $25(\mathrm{OH}) \mathrm{D}$ as a biomarker of available vitamin $\mathrm{D}$, while the biologically active form is its metabolite, 1,25-dihydroxyvitamin $\mathrm{D}$ or $1,25(\mathrm{OH})_{2} \mathrm{D}^{(15)} \cdot 25(\mathrm{OH}) \mathrm{D}$ has a circulating half-life of $15 \mathrm{~d}$ and is thus is a better marker of vitamin $\mathrm{D}$ repletion than $1,25(\mathrm{OH})_{2} \mathrm{D}$, which has a short circulating half-life of $15 \mathrm{~h}$ and is tightly regulated in blood serum by parathyroid hormone, $\mathrm{Ca}$, fibroblast growth factor-23 and phosphate ${ }^{(1)}$. However, in terms of non-bone-health-related conditions, uncertainty remains as to whether or not $25(\mathrm{OH}) \mathrm{D}$ status represents vitamin-D-related biological activity affecting disease risk or presence of other disease risk factors associated with $25(\mathrm{OH}) \mathrm{D}$ status ${ }^{(15)}$.

A 2010 Ontario study found that almost $40 \%$ of working-age Ontario women did not meet the Dietary Reference Intake for vitamin D of $5 \mu \mathrm{g} / \mathrm{d}(200 \mathrm{IU} / \mathrm{d})^{(16)}$, a percentage now likely to be even higher since the IOM has raised the daily requirement to a recommended dietary intake of $15 \mu \mathrm{g} / \mathrm{d}$ (600 IU/d) for females aged $1-70$ years ${ }^{(10)}$. Since the IOM estimates that mean daily vitamin D intake among Canadian women aged $19-50$ years ranges between 4.7 and $5.2 \mu \mathrm{g} / \mathrm{d}(188 \text { and } 208 \mathrm{IU} / \mathrm{d})^{(10)}$, vitamin $\mathrm{D}$ deficiency is a concern in this population and determinants of serum $25(\mathrm{OH})$ D concentration should be explored to help identify strategies for prevention. The objectives of the present study were to describe seasonal variation in serum $25(\mathrm{OH}) \mathrm{D}$ concentrations, prevalence of vitamin $\mathrm{D}$ inadequacy and deficiency, and the UV and dietary contributions to the prediction of serum $25(\mathrm{OH}) \mathrm{D}$ concentrations in a population of premenopausal nurses in Kingston, Ontario, Canada $\left(44^{\circ} \mathrm{N}\right)$.

\section{Experimental methods}

A cross-sectional study was conducted among premenopausal nurses from Kingston General Hospital who volunteered to participate. Recruitment began in April 2008 through posters, pamphlets and information sessions. Participants were full-time nurses working the shift schedule of two $12 \mathrm{~h}$ days followed by two $12 \mathrm{~h}$ nights, followed by five days off. Nurses self-excluded if they had used melatonin supplements or had been pregnant or lactating within the past 6 months. While ninety-four nurses provided informed consent for all aspects of data collection, eleven were excluded due to pregnancy, change to part-time status, failure to provide a blood sample or study withdrawal. Thus, eighty-three (88\%) nurses were included in the present analysis. Nurses participated in data collection for two seasonal time periods (winter/spring and summer/autumn) in either 2008 or 2009 to give two data collection periods for each nurse. All nurses completed data collection, with sixty-one participating in two seasons and twenty-two participating in only one season. The study was conducted according to the guidelines laid down in the Declaration of Helsinki and all procedures involving human subjects/ patients were approved by the Queen's University Health Sciences and Affiliated Teaching Hospitals Research Ethics Board. Written informed consent was obtained from all subjects/patients.

Weight and height were measured by a trained nurse for all but two participants who reported by telephone. Participants completed a questionnaire and provided an $8 \mathrm{~h}$ fasting blood sample upon waking prior to a day shift. Blood samples were collected in $3.5 \mathrm{ml}$ serum separator tubes, and isolated serum was separated into $100 \mu \mathrm{l}$ aliquots and stored in a dark $-80^{\circ} \mathrm{C}$ freezer. Total serum concentrations (nmol/l) of the biomarker 25(OH)D (representing both serum $25(\mathrm{OH}) \mathrm{D}_{2}$ and $25(\mathrm{OH}) \mathrm{D}_{3}$ ) were quantified using the DiaSorin 25(OH)D RIA, with all samples run in duplicate within each assay. Two counts per minute (CPM) values were thus calculated for each sample. For samples taken in the winter/spring, the intraassay CV for CPM values was $0.99(P<0.0001)$ and for samples taken in the summer/autumn, this value was 0.98 $(P<0 \cdot 0001)$. Within-assay quality control was ensured through calibration with six calibrator samples included with the RIA, where $\% \mathrm{~B} / \mathrm{B}_{0}$ was plotted $v \cdot \log$ concentration of the sample; $\% \mathrm{~B} / \mathrm{B}_{0}$ is defined as [(CPM of calibrator or unknown sample - CPM of non-specific binding buffer)/(CPM of 0 calibrator - CPM of non-specific binding buffer) $] \times 100 \%$.

The lifestyle section of the study questionnaire included type and frequency of vitamin D supplement use, tanning bed use, time spent outdoors from 11.00 to 15.00 hours in summer and early autumn, clothing coverage, sunscreen use and vacations to a sunny/warm destination taken within the last 6 months. The dietary section of the questionnaire focused on frequency of consumption of natural and fortified food sources of vitamin D in an average week in the past 6 months ${ }^{(17)}$. Both sections were adapted from the Ausimmune Study and used with permission from 
Dr Robyn Lucas, Canberra, Australia ${ }^{(18)}$. Skin type was selfclassified using Fitzpatrick's skin pigmentation scale ${ }^{(19)}$.

Mean serum 25(OH)D concentrations were calculated to describe monthly variation in vitamin $\mathrm{D}$ status, and

Table 1 Personal characteristics of the study population: female, premenopausal, shift-working nurses ( $n$ 83), Kingston, Ontario, Canada, April 2008 to July 2009

\begin{tabular}{|c|c|c|}
\hline Personal characteristic & $n$ & $\%$ \\
\hline \multicolumn{3}{|l|}{ Age (mean 35.8 (sD 8.3 ) years) } \\
\hline $22-29$ years & 24 & 29 \\
\hline $30-39$ years & 24 & 29 \\
\hline 40-44 years & 21 & 25 \\
\hline $45-53$ years & 14 & 17 \\
\hline \multicolumn{3}{|l|}{ BMI (mean $27 \cdot 3($ SD $\left.6 \cdot 7) \mathrm{kg} / \mathrm{m}^{2}\right)$} \\
\hline Normal weight/underweight* $\left(17 \cdot 3-24.9 \mathrm{~kg} / \mathrm{m}^{2}\right)$ & 38 & 46 \\
\hline Overweight $\left(25 \cdot 0-29 \cdot 9 \mathrm{~kg} / \mathrm{m}^{2}\right)$ & 28 & 34 \\
\hline Obese $\left(\geq 30 \cdot 0 \mathrm{~kg} / \mathrm{m}^{2}\right)$ & 17 & 20 \\
\hline \multicolumn{3}{|l|}{ Skin type } \\
\hline I (always burns, never tans) & 9 & 11 \\
\hline II (usually burns, tans with difficulty) & 21 & 25 \\
\hline III (sometimes burns mildly, tans gradually) & 39 & 47 \\
\hline IV (rarely burns, tans with ease) & 14 & 17 \\
\hline
\end{tabular}

*Only one nurse was underweight, so the underweight category was combined with the normal weight category. paired $t$ tests were performed to assess seasonal variation. General linear multivariable regression modelling was conducted to assess associations between potential determinants and serum $25(\mathrm{OH}) \mathrm{D}$ concentration following the winter/spring and summer/autumn seasons separately, while controlling for age and BMI. Generalized linear mixed models were used to allow for seasonal variation in solar UVB radiation by accounting for repeated observations over two seasons for the sixty-one participants with data for two seasons ${ }^{(20)}$. All models were assessed for potential confounders ${ }^{(21)}$. Statistical analyses were performed using the statistical software package SAS version $9 \cdot 2$.

\section{Results}

\section{Descriptive results}

Participants' mean age was 36 (SD 8.3) years, with mean BMI of just over $27 \mathrm{~kg} / \mathrm{m}^{2}$ (Table 1). Almost all nurses selfidentified as white, except five who were Asian, Latin or mixed. As seen in Table 2, lifestyle behaviours did not differ between seasons, although sunny vacations taken within

Table 2 Seasonal characteristics and behaviours of the study population: female, premenopausal, shift-working nurses ( $n$ 83), Kingston, Ontario, Canada, April 2008 to July 2009

\begin{tabular}{|c|c|c|c|c|}
\hline \multirow[b]{2}{*}{ Seasonal characteristic/behaviour } & \multicolumn{2}{|c|}{ Summer/autumn ( $n 74)$} & \multicolumn{2}{|c|}{ Winter/spring $(n 70)$} \\
\hline & Mean or $n$ & SD or $\%$ & Mean or $n$ & SD or $\%$ \\
\hline \multicolumn{5}{|l|}{ Serum 25(OH)D* (nmol/l) } \\
\hline Summer/autumn (median $87 \cdot 4 \mathrm{nmol} / \mathrm{l}$ ) & $93 \cdot 8$ & $42 \cdot 2$ & - & - \\
\hline Winter/spring (median $69.9 \mathrm{nmol} / \mathrm{l})$ & - & - & $73 \cdot 9$ & $26 \cdot 0$ \\
\hline \multicolumn{5}{|l|}{ Vitamin D status } \\
\hline Deficient (serum 25(OH)D < $30 \mathrm{nmol} / \mathrm{l})$ & 3 & 4 & 4 & 6 \\
\hline Inadequate $(30 \leq$ serum $25(\mathrm{OH}) \mathrm{D}<50 \mathrm{nmol} / \mathrm{l})$ & 4 & 5 & 5 & 7 \\
\hline Adequate (serum $25(\mathrm{OH}) \mathrm{D} \geq 50 \mathrm{nmol} / \mathrm{l})$ & 67 & 91 & 61 & 87 \\
\hline \multicolumn{5}{|l|}{ Lifestyle factors (previous 6 months) } \\
\hline \multicolumn{5}{|l|}{ Supplement use (including cod liver oil) } \\
\hline Yes & 32 & 43 & 29 & 42 \\
\hline No & 42 & 57 & 40 & 58 \\
\hline \multicolumn{5}{|l|}{ Time spent outdoors on work days } \\
\hline$<1 \mathrm{~h} / \mathrm{d}$ & 58 & 78 & - & - \\
\hline $1-3 \mathrm{~h} / \mathrm{d}$ & 16 & 22 & - & - \\
\hline \multicolumn{5}{|l|}{ Time spent outdoors on days off } \\
\hline$\leq 2 \mathrm{~h} / \mathrm{d}$ & 35 & 47 & - & - \\
\hline$>2 \mathrm{~h} / \mathrm{d}$ & 39 & 53 & - & - \\
\hline \multicolumn{5}{|l|}{ Time spent outdoors $11.00-15.00$ hours } \\
\hline$<1 \mathrm{~h} / \mathrm{d}$ & 22 & 57 & - & - \\
\hline $1-2 \mathrm{~h} / \mathrm{d}$ & 42 & 14 & - & - \\
\hline$\geq 2 \mathrm{~h} / \mathrm{d}$ & 10 & 30 & - & - \\
\hline \multicolumn{5}{|l|}{ Sunscreen use } \\
\hline$<50 \%$ of times outdoors & 50 & 68 & - & - \\
\hline$\geq 50 \%$ of times outdoors & 14 & 19 & - & - \\
\hline Always & 10 & 14 & - & - \\
\hline \multicolumn{5}{|l|}{ Tanning bed uset } \\
\hline Yes & 19 & 26 & 20 & 29 \\
\hline No & 55 & 74 & 49 & 70 \\
\hline \multicolumn{5}{|l|}{ Took a sunny vacationtł } \\
\hline Yes & 11 & 15 & 29 & 42 \\
\hline No & 63 & 85 & 40 & 58 \\
\hline
\end{tabular}

25(OH)D, 25-hydroxyvitamin D.

*Serum 25(OH)D data presented as mean and standard deviation; all other data presented as number and percentage.

tFrequency of tanning bed use ranged from once per week to a few times in 6 months.

$\ddagger$ Sunny vacation durations ranged from 6 to $18 \mathrm{~d}$ in length during the summer/autumn and from 6 to $28 \mathrm{~d}$ in length during the winter/spring. 


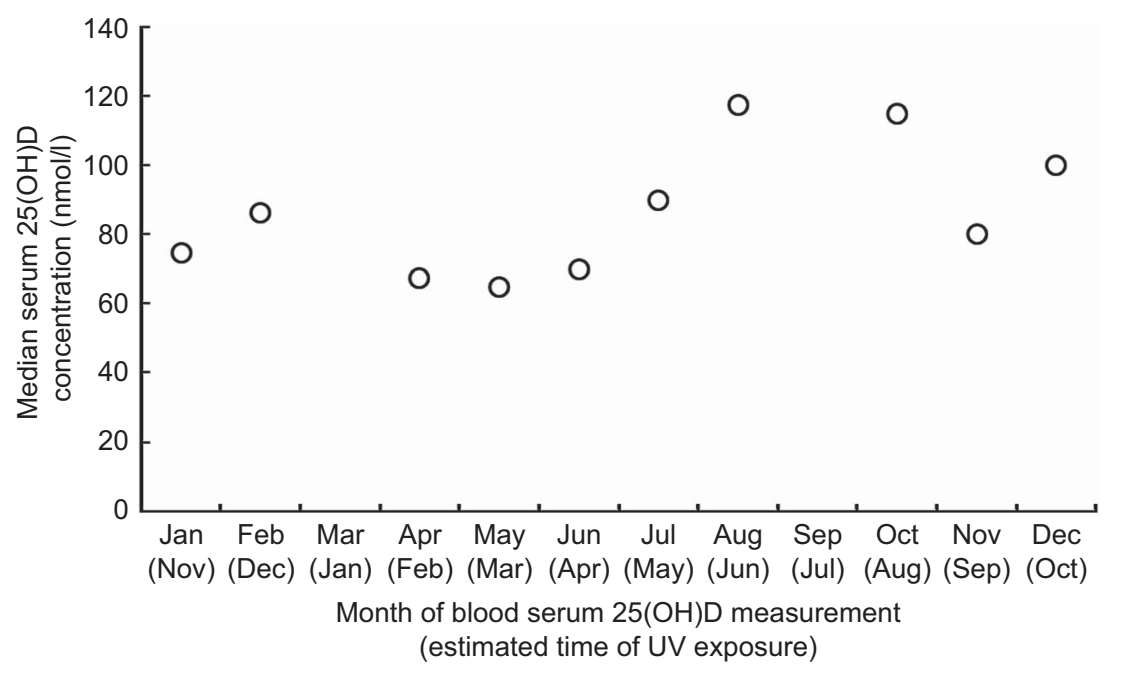

Fig. 1 Median serum 25-hydroxyvitamin $D(25(\mathrm{OH}) \mathrm{D})$ concentration by month among the study population: female, premenopausal, shift-working nurses ( $n$ 83), Kingston, Ontario, Canada, April 2008 to July 2009. No data were collected in March or September

the past 6 months were reported more frequently in the winter/spring (42\%) than in the summer/autumn (15\%).

\section{Serum 25-bydroxyvitamin $D$ concentration}

Median serum 25(OH)D concentration was higher during summer/autumn $(87 \cdot 4 \mathrm{nmol} / \mathrm{l})$ than during winter/spring (69.9 nmol/1). Following summer/autumn months, $4 \%$ of women were vitamin D deficient and another 5\% had inadequate concentrations for bone health. Following winter/spring months, these percentages were $6 \%$ and $7 \%$, respectively. Summer/autumn and winter/spring serum $25(\mathrm{OH}) \mathrm{D}$ concentrations were moderately positively correlated, with a Spearman's rank correlation coefficient of $0 \cdot 69$.

Median serum 25(OH)D concentrations among nurses by calendar month are displayed in Fig. 1. Median concentrations ranged from $65 \mathrm{nmol} / \mathrm{l}$ (May) to $117 \mathrm{nmol} / \mathrm{l}$ (August). Greater variation in individual serum 25(OH)D concentrations was observed following summer/autumn months (range 16-250 nmol/1) than following winter/spring months (17-135 nmol/1). No toxic 25(OH)D concentration was observed. Paired $t$ tests detected a difference in mean serum $25(\mathrm{OH}) \mathrm{D}$ concentrations between the two seasonal data collection periods $(P<0 \cdot 0001)$.

\section{Predictors of serum 25-bydroxyvitamin $D$ concentration}

Table 3 shows seasonal predictors of serum 25(OH)D concentrations. When seasons were analysed separately, tanning bed use during summer/autumn and winter/ spring was a significant predictor of serum 25(OH)D $(P<0 \cdot 0001$ and $P=0 \cdot 03$, respectively), while vitamin D supplement use in summer/autumn and time spent outdoors between 11.00 and 15.00 hours in summer/autumn were of borderline significance $(P=0.05$ and $P=0.06$, respectively). Dietary factors, skin pigmentation, sunscreen use and having taken a vacation to a sunny/warm destination in the past 6 months were not associated with serum 25(OH)D concentration in either season, and vitamin D supplement use was not associated with serum $25(\mathrm{OH}) \mathrm{D}$ concentration in the winter/spring. These variables were subsequently not included in final models. When seasons were analysed together, tanning bed use in the past 6 months was associated with an increase in serum $25(\mathrm{OH}) \mathrm{D}$ concentration of $23 \cdot 24 \mathrm{nmol} / 1$ on average (95\% CI $8 \cdot 78,37 \cdot 69 \mathrm{nmol} / 1, P=0 \cdot 002)$.

\section{Discussion}

In the present cross-sectional study of female nurses in Ontario, Canada, we found that serum 25(OH)D concentrations tended towards the low end of the adequate range for bone health ( $\geq 50 \mathrm{nmol} / \mathrm{l})$. After summer/ autumn, $9 \%$ of women had deficient or inadequate serum $25(\mathrm{OH}) \mathrm{D}$ and after winter/spring this proportion was $13 \%$. According to the 2011 IOM vitamin D guidelines for bone health, these women are at increased risk for osteoporosis and/or osteomalacia. Tanning bed use was the strongest modifiable predictor that we identified to increase serum 25(OH)D concentration, followed by use of vitamin D supplements.

Vitamin D supplementation was a significant determinant of serum $25(\mathrm{OH}) \mathrm{D}$ concentrations in the summer/ autumn season. One other study also found this result, attributed in that study to confounding by time spent outdoors during the summer ${ }^{(22)}$. In our analysis we did control for time spent outdoors, and vitamin D supplementation remained a statistically significant predictor of serum 25(OH)D concentration. Our results are consistent 
with previous reports demonstrating that supplement use improves serum 25(OH)D concentration and prevents deficiency ${ }^{(7,23)}$. Supplement use is a safe means to improve vitamin D status compared with potential harm from solar or artificial UV exposure: the IOM reports an upper tolerable limit of $100 \mu \mathrm{g} / \mathrm{d}$ (4000 IU/d), a relatively high amount ${ }^{(10)}$.

While previous studies have identified foods containing vitamin $\mathrm{D}$ as predictors of serum $25(\mathrm{OH}) \mathrm{D}$ concentration following the winter ${ }^{(6-8)}$, particularly milk ${ }^{(24,25)}$, we did not find any association with dietary sources of vitamin D. Because the vitamin D content of most foods is low relative to the amount produced in skin ${ }^{(5)}$, we may not have been able to detect the relatively small contribution of diet. Skin type, another factor known to be associated with vitamin $\mathrm{D}$ status, was not associated with serum $25(\mathrm{OH}) \mathrm{D}$ concentration in our study likely because of the lack of variation in this factor as almost all women in our study were white.

Recent data from the 2007-2009 Canadian Health Measures Survey (CHMS) also using the current IOM guidelines report that prevalence of deficient or inadequate vitamin D status is $20 \%$ among women aged 20-39 years across Canada following summer and 31\% following winter ${ }^{(26)}$. Other studies conducted at similar latitudes have noted as much as $73 \%$ of their study population to have inadequate vitamin D status ${ }^{(6,27)}$. We may have observed a comparatively low proportion with deficient and inadequate vitamin $\mathrm{D}$ status because younger age, white ethnicity, higher BMI and tanning bed use were prevalent in our study population and are associated with protection against deficient and inadequate vitamin D status ${ }^{(5-8)}$. Despite these protective characteristics, deficient and inadequate vitamin D status was not rare in our study following the winter/spring months. Together, results from our study and others support the need to find ways to increase vitamin D status especially during winter months.

While just less than $30 \%$ of study participants used a tanning bed in the 6 months prior to answering the questionnaire, this habit was a strong predictor of serum $25(\mathrm{OH}) \mathrm{D}$ concentration. The proportion of women reporting tanning bed use in our study is higher than the national average for Canada, where $15 \%$ of women aged 25- 44 years reported tanning bed use in the 2006 National Sun Survey ${ }^{(28)}$. Tanning bed use is most common among white ethnic groups and among higher income groups ${ }^{(29,30)}$ as represented by the working nurses in our study, which may be why tanning bed use was more common in our study than among the general Canadian population of the same age and gender. Although the tanning industry claims that tanning bed use helps prevent vitamin $\mathrm{D}$ deficiency ${ }^{(31)}$, the health hazards from exposure to tanning beds are well documented ${ }^{(32)}$. Tanning beds emit variable amounts of UVA and UVB radiation in doses often higher than that emitted by the 
sun, resulting in increased risk for UV overexposure ${ }^{(32)}$. The International Agency for Research on Cancer has classified tanning beds as a cause of skin cancer ${ }^{(33)}$, supported by extensive literature showing that their use causes higher risks for melanoma and other skin cancers $^{(34,35)}$. Tanning bed use is not advocated as a safe form of obtaining UV exposure for vitamin D synthesis and should not be used to obtain vitamin D among otherwise healthy populations ${ }^{(34)}$.

Legislation in many countries is being implemented to prevent harmful exposure from tanning beds specifically among young women and teens, with Brazil becoming the first country to ban commercial tanning bed use altogether ${ }^{(36)}$. Within Canada, legislation banning tanning beds among minors and enforcing other safety regulations exists in New Brunswick and in Victoria, British Columbia; was introduced into Ontario Parliament on 7 March 2013; and is anticipated in other provinces ${ }^{(37,38)}$. Young white women are the population subgroup with the highest rate of tanning bed use ${ }^{(29,30)}$, and in Ontario and nationally this group is most unlikely to meet the daily dietary required intake for vitamin $\mathrm{D}^{(10,16,23)}$. As tanning bed use is increasingly curtailed, our study supports the need for increasing emphasis on vitamin D supplementation, especially in the winter months.

The present research has several strengths. Vitamin D status was measured using the objective serum biomarker, $25(\mathrm{OH}) \mathrm{D}$. Although the utility of $25(\mathrm{OH}) \mathrm{D}$ in representing risk for non-bone-related health conditions is uncertain, this biomarker is the best biomarker of vitamin D status ${ }^{(1)}$. Although we did not assess betweenassay variation, the within-assay correlations between samples run in duplicate were extremely high and all assays were performed by a single technician. Our study population of premenopausal women is of particular public health importance with respect to vitamin $\mathrm{D}$, as young white women are the population subgroup most at risk in North America for low vitamin D status and engaging in tanning behaviours ${ }^{(10,29,30)}$. Studies similar to ours have been conducted in other global locations and latitudes $s^{(7,8,22,25,39,40)}$, although few studies have been conducted in Canada and these were prior to the recent IOM report ${ }^{(6,24,25,41)}$. The CHMS analysis was performed according to the 2011 IOM guidelines, although our study additionally examined monthly vitamin $\mathrm{D}$ variation and tanning bed use. Our descriptive assessment of monthly $25(\mathrm{OH}) \mathrm{D}$ concentrations allowed enhanced precision in measurement of annual variation in vitamin $\mathrm{D}$ status and supports the concept of a "vitamin D winter" (4). The examination of tanning bed use as a predictor of vitamin D status according to the 2011 IOM guidelines has not yet been done in Canada outside the present study.

The study is not without limitations. Our small sample size and relatively homogeneous study population of white, working-age, female nurses may have reduced our ability to detect predictors of serum $25(\mathrm{OH}) \mathrm{D}$ concentration that have small variability in our population. Regarding generalizability, results can be confidently extrapolated to white, working-age women at approximately the same latitude $\left(44^{\circ} \mathrm{N}\right)$. Sample size limitations reduced the precision of estimates in our multivariable single season models, which may explain why the effect for tanning bed use was smaller in the winter/spring relative to summer/autumn and why supplementation had a nonstatistically significant effect in the winter/spring. Some degree of recall error non-differential by vitamin D status may have occurred with our self-report questionnaire, causing our results to underestimate the effects of tanning bed use, supplement use and other factors on vitamin D status. However, a self-report questionnaire of past sun exposure with questions similar to ours has been shown to be valid when compared with objective measures of UV skin damage and serum 25(OH)D and test-retest $\kappa$ statistics ranging from 0.43 to 0.74 for self-reported sun exposure $^{(42)}$. Misclassification of skin type was possible, as validity of the Fitzpatrick classification system has been questioned due to its dependence on self-reported data $^{(19,43)}$, although this scale is used internationally. Diet was assessed descriptively, rather than through objective measures $^{(44)}$.

\section{Conclusions}

Although we found that most nurses had adequate serum vitamin D status for bone health, $13 \%$ were at risk for osteoporosis and/or osteomalacia following winter months. Women who use tanning beds are likely to be at increased risk for premature skin ageing and skin cancers; these health risks outweigh any perceived benefits of tanning bed use. Public health strategies promoting vitamin D supplementation and consumption of fortified foods (e.g. fortified milk) are essential to protect against osteopenia and osteomalacia among this population subgroup. While the biological activity of vitamin D in relation to non-bony disease risk becomes better understood through research ${ }^{(15)}$, we must take action now to improve the vitamin D status of young women while enforcing safe sun practices and recommendations against tanning bed use.

\section{Acknowledgements}

Sources of funding: Financial support for this research was provided by the Workplace Safety and Insurance Board (Ontario, Canada). S.C.W. was supported by the Terry Fox Foundation/Canadian Institutes of Health Research Transdisciplinary Training Program in Cancer Research at Queen's University. J.T. was supported by a Mid-Career Investigator Award for the Ontario Women's Health Council/Canadian Institutes of Health Research. Conflict of interest: The authors have no conflicting interests. 
Authors' contributions: S.C.W. performed the RIA for serum 25(OH)D and the statistical analysis and contributed to interpretation of the results and drafting of the manuscript. G.J. oversaw the RIA, contributed to interpretation of the results and provided revisions of the manuscript. L.C.K. performed the statistical analysis and contributed to interpretation of the results and drafting of the manuscript. A.G. contributed to the study design and provided revisions of the manuscript. Q.M. performed the statistical analysis and contributed to interpretation of the results. J.T. contributed to the study design, coordination and participant recruitment. K.J.A. conceived of the study, contributed to its design and coordination, directed the analysis and provided revisions of the manuscript. All authors have seen and approved the contents of this manuscript. Acknowledgements: The authors thank the nurses who participated in the study; the co-investigators of the larger study, Drs Harriet Richardson, Ian Janssen and Charles Graham; the study staff, Kathy Bowes, Deborah Emerton, Karen Lollar, Krista Smith, Shannyn McDonald-Goodfellow and Mark McPherson; Valarie Byford and Martin Kaufmann for their support with laboratory analyses; and Dr Robyn Lucas for providing permission to adapt sections of the Ausimmune Study questionnaire.

\section{References}

1. Office of Dietary Supplements, National Institutes of Health (2011) Dietary Supplement Fact Sheet: Vitamin D for Health Professionals. http://ods.od.nih.gov/factsheets/vitamind.asp (accessed June 2013).

2. Lucas JA, Bolland MJ, Grey AB et al. (2005) Determinants of vitamin D status in older women living in a subtropical climate. Osteoporos Int 16, 1641-1648.

3. Holick MF (1995) Environmental factors that influence the cutaneous production of vitamin D. Am J Clin Nutr 61, Suppl. 3, S638-S645.

4. Engelsen O, Brustad M, Aksnes L et al. (2005) Daily duration of vitamin D synthesis in human skin with relation to latitude, total ozone, altitude, ground cover, aerosols and cloud thickness. Photochem Photobiol 81, 1287-1290.

5. Chen TC, Chimeh F, Lu Z et al. (2007) Factors that influence the cutaneous synthesis and dietary sources of vitamin D. Arch Biochem Biophys 460, 213-217.

6. Gozdzik A, Barta J, Wu H et al. (2008) Low wintertime vitamin D levels in a sample of healthy young adults of diverse ancestry living in the Toronto area: associations with vitamin D intake and skin pigmentation. BMC Public Health 8, 336.

7. Burgaz A, Akesson A, Oster A et al. (2007) Associations of diet, supplement use, and ultraviolet $\mathrm{B}$ radiation exposure with vitamin D status in Swedish women during winter. Am J Clin Nutr 86, 1399-1404.

8. Tangpricha V, Turner A, Spina C et al. (2004) Tanning is associated with optimal vitamin D status (serum 25-hydroxyvitamin D concentration) and higher bone mineral density. Am J Clin Nutr 80, 1645-1649.

9. Jones $\mathrm{G}$ (2008) Pharmacokinetics of vitamin D toxicity. Am J Clin Nutr 88, issue 2, 582S-586S.

10. Committee to Review Dietary Reference Intakes for Vitamin D and Calcium, Institute of Medicine (2011)
Dietary Reference Intakes for Calcium and Vitamin D [AC Ross, CL Taylor, YL Yaktine et al., editors]. Washington, DC: The National Academies Press.

11. Holick MF (2007) Vitamin D deficiency. N Engl J Med 357, 266-281.

12. Munger KL, Levin LI, Hollis BW et al. (2006) Serum 25-hydroxyvitamin D levels and risk of multiple sclerosis. JAMA 296, 2832-2838.

13. Yang L, Veierød MB, Löf M et al. (2011) Prospective study of UV exposure and cancer incidence among Swedish women. Cancer Epidemiol Biomarkers Prev 20, 1358-1367.

14. Anderson LN, Cotterchio M, Kirsh VA et al. (2011) Ultraviolet sunlight exposure during adolescence and adulthood and breast cancer risk: a population-based case-control study among Ontario women. Am J Epidemiol 174, 293-304.

15. Jacobs ET, Martinez ME \& Jurutka PW (2011) Vitamin D: marker or mechanism of action? Cancer Epidemiol Biomarkers Prev 20, 585-590.

16. Anderson LN, Cotterchio M, Boucher BA et al. (2010) Vitamin D intake from food and supplements among Ontario women based on the US Block Food Frequency Questionnaire with and without modifications for Canadian food values. Can J Public Health 101, 318-321.

17. Bolek-Berquist J, Elliott ME, Gangnon RE et al. (2009) Use of a questionnaire to assess vitamin D status in young adults. Public Health Nutr 12, 236-243.

18. Lucas RM, Ponsonby A-L, McMichael AJ et al. (2007) Observational analytic studies in multiple sclerosis: controlling bias through study design and conduct. The Australian Multicentre Study of Environment and Immune Function. Mult Scler 13, 827-839.

19. Fitzpatrick TB (1988) The validity and practicality of sun-reactive skin types I through VI. Arch Dermatol 124, 869-871.

20. Littell RC, Stroup WW \& Freund RJ (2002) Repeated measures analysis. In SAS for Linear Models, 4th ed., pp. 265-304 [RC Littell, WW Stroup and RJ Freund, editors]. Cary, NC: SAS Institute Inc.

21. Rothman KJ \& Greenland S (1998) Introduction to stratified analysis. In Modern Epidemiology, 2nd ed., pp. 253-280 [KJ Rothman and S Greenland, editors]. Philadelphia, PA: Lippincott Williams \& Wilkins.

22. Vieth R, Cole DE, Hawker GA et al. (2001) Wintertime vitamin D insufficiency is common in young Canadian women, and their vitamin D intake does not prevent it. Eur J Clin Nutr 55, 1091-1097.

23. Nelson ML, Blum JM, Hollis BW et al. (2009) Supplements of $20 \mu \mathrm{g} / \mathrm{d}$ cholecalciferol optimized serum 25-hydroxyvitamin D concentrations in $80 \%$ of premenopausal women in winter. J Nutr 139, 540-546.

24. Greenfield JA, Park PS, Farahani E et al. (2012) Solar ultraviolet-B radiation and vitamin D: a cross-sectional population-based study using data from the 2007 to 2009 Canadian Health Measures Survey. BMC Public Health 12, 660 .

25. Sahota H, Barnett H, Lesosky M et al. (2008) Association of vitamin D-related information from a telephone interview with 25-hydroxyvitamin D. Cancer Epidemiol Biomarkers Prev 17, 232-238.

26. Whiting SJ, Langlois KA, Vatanparast $\mathrm{H}$ et al. (2011) The vitamin D status of Canadians relative to the 2011 dietary reference intakes: an examination in children and adults with and without supplement use. Am J Clin Nutr 94, 128-135.

27. Kull M Jr, Kallikorm R, Tamm A et al. (2009) Seasonal variance of $25-(\mathrm{OH})$ vitamin $\mathrm{D}$ in the general population of Estonia, a northern European country. BMC Public Health 9, 22 .

28. National Skin Cancer Prevention Committee (2010) Exposure to and Protection from the Sun in Canada: A Report 
Based on the 2006 Second National Sun Survey. Toronto: Canadian Partnership Against Cancer; available at http:// www.partnershipagainstcancer.ca/wp-content/uploads/ Exposure-to-and-Protection-from-the-Sun-in-Canada.pdf

29. Hartman AM, Guy GP Jr, Holman DM et al. (2012) Use of indoor tanning devices by adults - United States, 2010. MMWR Morbid Mortal Wkly Rep 61, 323-326.

30. Woo DK \& Eide MJ (2010) Tanning beds, skin cancer, and vitamin D: an examination of the scientific evidence and public health implications. Dermatol Ther 23, 61-71.

31. Autier P, Dore JF, Breitbart E et al. (2011) The indoor tanning industry's double game. Lancet 377, 1299-1301.

32. Lim HW, James WD, Rigel DS et al. (2011) Adverse effects of ultraviolet radiation from the use of indoor tanning equipment: time to ban the tan. J Am Acad Dermatol 64 e51-e60.

33. El Ghissassi F, Baan R, Straif K et al., on behalf of the WHO International Agency for Research on Cancer Monograph Working Group (2009) A review of human carcinogens part D: radiation. Lancet Oncol 10, 751-752.

34. IARC Working Group (2006) The association of use of sunbeds with cutaneous malignant melanoma and other skin cancers: a systematic review. Int J Cancer 120, 1116-1122.

35. Gallagher RP, Spinelli JJ \& Lee TK (2005) Tanning beds, sunlamps, and risk of cutaneous malignant melanoma. Cancer Epidemiol Biomarkers Prev 14, 562-566.

36. Collegiate Board of Directors, Brazilian National Health Surveillance Agency (2009) Resolution: RDC no. 56. Brasilia: The Collegiate Board of Directors.
37. Matthews Hon D (2013) Bill 30, Skin Cancer Prevention Act (Tanning Beds), 2013. Ottawa: Legislative Assembly of Ontario; available at http://www.ontla.on.ca/web/bills/ bills_detail.do?locale $=$ en $\&$ BillID $=2748 \&$ detailPage $=$ bills_ detail_the_bill

38. Capital Regional District (2011) CRD Board Passes Tanning Bylaw. Victoria: Capital Regional District; available at http://www.crd.bc.ca/media/2011-01-12-tanning-bylaw.htm

39. Brot C, Vestergaard P, Kolthoff $\mathrm{N}$ et al. (2001) Vitamin D status and its adequacy in healthy Danish perimenopausal women: relationships to dietary intake, sun exposure and serum parathyroid hormone. BrJ Nutr 86, Suppl. 1, 97-103.

40. Nesby-O'Dell S, Scanlon KS, Cogswell ME et al. (2002) Hypovitaminosis D prevalence and determinants among African American and white women of reproductive age: third National Health and Nutrition Examination Survey, 1988-1994. Am J Clin Nutr 76, 187-192.

41. Rucker D, Allan JA, Fick GH et al. (2002) Vitamin D insufficiency in a population of healthy western Canadians. CMAJ 166, 1517-1524.

42. van der Mei IAF, Blizzard L, Ponsonby A-L et al. (2006) Validity and reliability of adult recall of past sun exposure in a case-control study of multiple sclerosis. Cancer Epidemiol Biomarkers Prev 15, 1538-1544.

43. Rampen FHJ, Fleuren BAM, Boo TMD et al. (1988) Unreliability of self-reported burning tendency and tanning ability. Arch Dermatol 124, 885-888.

44. Millen AE \& Bodnar LM (2008) Vitamin D assessment in population-based studies: a review of the issues. Am J Clin Nutr 87, 1102-1105. 